\title{
Over-Pressurized Bioreactors: Application to Microbial Cell Cultures
}

\author{
Marlene Lopes, Isabel Belo, and Manuel Mota \\ Center of Biological Engineering, University of Minho, Campus de Gualtar, Braga 4710-057 Portugal
}

DOI 10.1002/btpr.1917

Published online May 8, 2014 in Wiley Online Library (wileyonlinelibrary.com)

In industrial biotechnology, microbial cultures are exposed to different local pressures inside bioreactors. Depending on the microbial species and strains, the increased pressure may have detrimental or beneficial effects on cellular growth and product formation. In this review, the effects of increased air pressure on various microbial cultures growing in bioreactors under moderate total pressure conditions (maximum, 15 bar) will be discussed. Recent data illustrating the diversity of increased air pressure effects at different levels in microbial cells cultivation will be presented, with particular attention to the effects of oxygen and carbon dioxide partial pressures on cellular growth and product formation, and the concomitant effect of oxygen pressure on antioxidant cellular defense mechanisms. (c) 2014 American Institute of Chemical Engineers Biotechnol. Prog., 30:767-775, 2014

Keywords: pressurized bioreactors, oxygen mass transfer rate, cellular growth, product formation, reactive oxygen species, antioxidant enzymes

\section{Introduction}

In industrial processes, microorganisms are required to have an efficient metabolism, with high productivities, to accomplish an economical production process. In a typical industrial aerobic cell cultivation system, high cell densities are reached, with oxygen being the usual major growth limiting factor. The use of increased total pressure in bioreactors may be a way of improving oxygen-transfer rate (OTR) from air to aerobic cultures, avoiding oxygen limitation. ${ }^{1-5}$

On the other hand, during a biotechnological process, based on microbial cultures, differences in environmental conditions may occur, such as pressure gradients, and consequently on dissolved gas compounds concentration, leading to changes in cellular metabolism. In fact, owing to the differences observed in the residence time distribution in large bioreactors, cells are distinctly exposed to high pressures (at the bottom) and to low pressures (on top). Inside the bioreactor, the total pressure in each point is the sum of operational pressure (pressure at the top of the reactor) and the hydrostatic pressure exerted by the liquid height above this point. As a consequence, equilibrium solubilities of gaseous compounds will also be a function of the local position inside the reactor. Therefore, in an industrial bioreactor containing a liquid medium up to a level of $10 \mathrm{~m}$ and with a pressure at the top of 1.5 bar, total pressure at the bottom will amount to 2.5 bar, meaning that gas solubility, for example for oxygen or carbon dioxide at the bottom, will be nearly $70 \%$ higher than at the top of the bioreactor. ${ }^{6}$

The effects of these pressures have to be taken into account when scaling up as many differences in process productivities found between the R\&D phase (lab-scale) and the production phase (industrial scale) can be partially explained by these different environmental conditions.

Correspondence concerning this article should be addressed to: M. Mota atmmota@deb.uminho.pt
The influence of increased air pressure on microbial behavior is strongly dependent on species and strains owing to the different cellular responses to oxidative stress. Above certain limits, increased oxygen partial pressure, as a consequence of air pressure raise, may have harmful effects on microbial cell activity and on products formation. In overpressurized bioreactors, cells are often exposed to $\mathrm{O}_{2}$ partial pressures above 0.21 bar (corresponding to air at 1 bar), leading to the formation of reactive oxygen species (ROS) (Figure 1). To counter oxidative stress imposed by these species, cells constitutively express enzymes that detoxify the ROS and repair the damage incurred.

Thus, it is very important to assess the impact of increased air pressure on cellular physiology of diverse microbial species for possible application in bioprocess optimization and development. The purpose of this article is to review the relevant available knowledge about the effects of increased air pressure on microbial cultures.

\section{Mass transfer under increased air pressure}

The adequate oxygen supply in the biotechnological processes is crucial to the growth and maintenance of most aerobic microbial cultures. Oxygen mass transfer from the gas phase to the liquid medium is often a major growth-limiting factor owing to the low oxygen solubility in an aqueous solution. ${ }^{7}$ Thus, it is important to ensure an adequate oxygen supply to submerged cultures.

The use of increased air pressure to improve the oxygen mass transfer from the gas phase to the liquid has been proposed by some authors. ${ }^{1,4,5,8}$

\section{Dissolved oxygen}

Aerobic bioprocesses are generally carried out in an aqueous media, where the solubility of oxygen is low, and even reduced by the presence of nutrients and ionic salts, whereas 


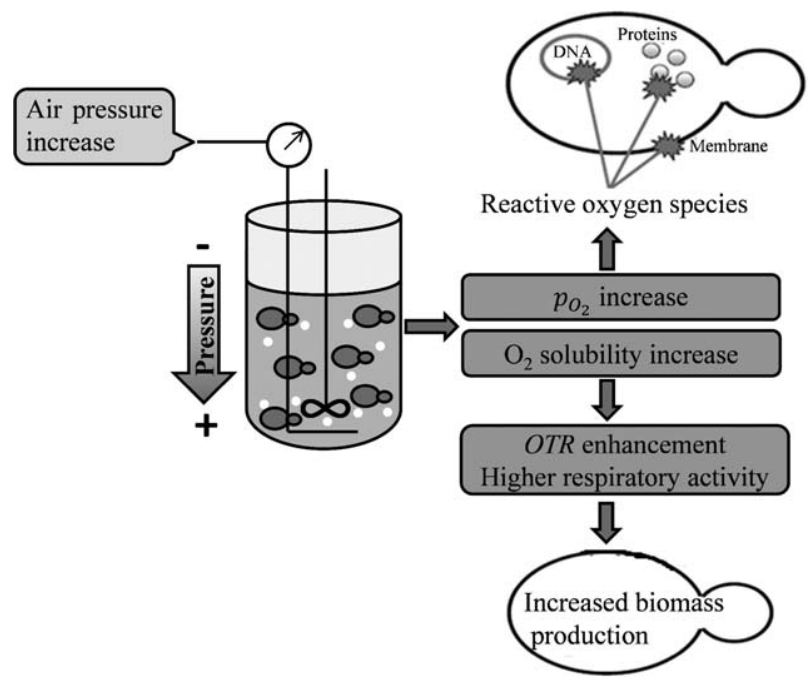

Figure 1. Overview of air pressure impact on microbial cell cultivation: oxygen mass transfer, microbial growth, and oxidative stress.

the oxygen demand of microbial cultures is high. ${ }^{9,10}$ As a consequence, oxygen mass transfer between gas phase and liquid phase is an important and rate-limiting step.

There are several methods to enhance oxygen mass transfer rate to a culture: increasing air flow rate and/or stirring speed, or enriching inlet air with pure oxygen. ${ }^{11}$ Other nonconventional methods to enhance the oxygen supply include coimmobilization or mixed culture with oxygen-producing photosynthetic algae, ${ }^{12,13}$ in situ generation of molecular oxygen with hydrogen peroxide and catalase, ${ }^{14,15}$ and the introduction of an immiscible phase of perfluorocarbons ${ }^{16}$ with high oxygen solubility. Nevertheless, these strategies are limited by one or more factors, namely, increased cost of downstream processing to remove the added chemicals, toxicity, chemical compatibility, competition for common nutrients, and complications in bioreactor design and operation. ${ }^{17}$

The use of increased air pressure is a simple alternative of improving microbial cultures oxygenation owing to its impact on oxygen solubility, as described below.

The mass balance for the dissolved oxygen in the wellmixed liquid phase, for a batch system, can be established as:

$$
\frac{d C_{\mathrm{L}}}{d t}=\mathrm{OTR}-\mathrm{OUR}
$$

where $C_{\mathrm{L}}$ is the dissolved oxygen concentration in the medium, $t$ is the time, OTR is the oxygen mass transfer rate from the gas phase into the broth, and OUR is the oxygen uptake rate by the microorganisms.

OUR depends on the biological system and can be expressed as the product of the specific oxygen consumption rate of the microorganism $\left(q_{\mathrm{O}_{2}}\right)$ and the biomass concentration $(X)$ :

$$
\text { OUR }=q_{\mathrm{O}_{2}} \cdot X
$$

OTR is controlled by the driven force for mass transfer, that is, the difference between the oxygen solubility $\left(C^{*}\right)$, which depends on medium composition and temperature, and $C_{\mathrm{L}}$, and the volumetric oxygen mass-transfer coefficient $\left(K_{\mathrm{L}} a\right)$, which depends on the bioreactor design and operating conditions, according to Eq. (3):

$$
\mathrm{OTR}=K_{\mathrm{L}} a\left(C^{*}-C_{\mathrm{L}}\right)
$$

The oxygen solubility in the liquid medium can be raised by increasing the total air pressure in the cultivation system. The saturation concentration of oxygen from air in broth, $C^{*}$, is affected by the oxygen partial pressure $\left(p_{\mathrm{O}_{2}}\right)$, according to Henry's law (Eq. (4)):

$$
p_{\mathrm{O}_{2}}=H_{\mathrm{O}_{2}} \cdot C^{*}
$$

where $H_{\mathrm{O}_{2}}$ is the Henry constant, and $p_{\mathrm{O}_{2}}$ is related with $P_{\mathrm{T}}$, the total air pressure and $y_{\mathrm{O}_{2}}$, the oxygen molar fraction in the gas according to Dalton law (Eq. (5)).

$$
p_{\mathrm{O}_{2}}=y_{\mathrm{O}_{2}} \cdot P_{\mathrm{T}}
$$

According to Eq. (1), to keep dissolved oxygen at a constant value in a microbial culture, for example, $d C_{\mathrm{L}} / d t$ equal to zero, OTR must be equal to or higher than OUR. This last parameter increases dramatically as the cell density in a bioreactor also increases (Eq. (2)), leading to the need of operating with conditions that allow high OTR values.

Published studies have reported the use of increased air pressure to improve the OTR for cell cultivation.

Belo et al. ${ }^{18}$ showed that the increase of oxygen solubility owing to the bioreactor pressurization resulted in the improvement of the OTR, demonstrating the positive effects of pressure on the OTR of the system. With an air supply at constant mass flow rate, the OTR increased proportionally to the 1.3 power of oxygen solubility. Also, Follonier et al. ${ }^{19}$ reported that a 10 -fold increase of pressure can enhance the oxygen solubility by about a factor of 10 .

Yang and Wang ${ }^{17}$ reported that the bioreactor headspace pressurization increased 2.7 times the OTR in the bulk medium for operating pressures up to 2.7 bar. Belo et al. ${ }^{1}$ reported a sixfold improvement in OTR when the total air pressure increased from 1 to 5.6 bar. Pinheiro et al. ${ }^{5}$ demonstrated that OTR, in a cylindrical bioreactor without mechanical agitation, is clearly enhanced by air pressure raising from 1.2 to 6 bar, obtaining values of $316 \mathrm{mg} \mathrm{O}_{2} /(\mathrm{L} \mathrm{h})$ and $1,099 \mathrm{mg} \mathrm{O}_{2} /(\mathrm{L} \mathrm{h})$, respectively. Knoll et al. ${ }^{3}$ showed that increasing air pressure up to 11 bar could be a way of improving OTR of microbial cultures with energy cost efficiencies acceptable for industrial application. Also, Knoll et al. $^{8}$ during a Escherichia coli fed-batch cultivation, achieved approximately a twofold improvement in OTR by increasing stepwise the air pressure from 1 to 11 bar. Lopes et al. $^{4}$ observed a 2.3 -fold increase of OTR in a bioreactor without mechanical agitation by shifting the total air pressure from 2 to 8 bar. In addition, in a mechanical stirred bioreactor, a threefold improvement in OTR by increasing air pressure from 1 to 5 bar was reported. ${ }^{20}$

OTR in a stirred tank bioreactor has been estimated through $K_{\mathrm{L}} a$ correlations with specific power input and gas velocity, that are the major operational factors traditionally manipulated to improve OTR. ${ }^{21}$ In pressurized bioreactors, the pressure effect must also be considered in the OTR estimation. Thus, OTR was correlated as a function of the product of the power of those factors, as expressed by the following equation:

$$
\mathrm{OTR}=\alpha\left(\frac{P_{\mathrm{g}}}{V}\right)^{\delta}\left(v_{\mathrm{s}}\right)^{\gamma}(P)^{\beta}
$$

being the exponent of pressure close to unit, ${ }^{4,22,23}$ the specific power input $P_{\mathrm{g}} / V$ exponent $\delta$ around 0.7 and the $v_{s}$ 
exponent $\gamma$ around $0.48 .^{3,22}$ Based on Eq. (6) and in the exponents found by Lopes et al., ${ }^{22}$ we may conclude that pressure is the factor that has a stronger impact on OTR than agitation and aeration rates. In addition, it is possible to keep the same value of OTR by increasing air pressure and decreasing the specific power input as shown in Figure 2, leading to important energy cost savings. In addition, cultivation under pressurized conditions presents positive economic advantages in OTR improvement compared to oxygen-enriched air strategies. ${ }^{17}$

\section{Dissolved carbon dioxide}

In the aerobic or fermentative processes, carbon dioxide is a component that must also be considered as it is not only a product of decarboxylation reactions, but also a substrate in carboxylation reactions required for the production of important intermediates from metabolic sequences. ${ }^{6}$ Thus, the $\mathrm{CO}_{2}$ produced in the respiration could be reused by the cells. However, the microbial respiratory activity overall balance shows a $\mathrm{CO}_{2}$ superfluous production that will be dissolved in the medium. The oversaturation of the medium with $\mathrm{CO}_{2}$ will depend on the amount of $\mathrm{CO}_{2}$ stripped by continuous aeration.

Similarly as shown for oxygen in Eq. (1), the mass balance for the dissolved carbon dioxide in an aerobic culture, for a batch system, can be established as:

$$
\frac{d \mathrm{CO}_{2}}{d t}=\mathrm{CER}-\mathrm{CTR}
$$

where $\mathrm{CO}_{2}$ is the dissolved carbon dioxide concentration in the medium, CER is the carbon dioxide production rate, and CTR is the carbon dioxide-transfer rate from the liquid phase to the gas phase.

The CER is related to the microorganism growth rate as well as with the metabolic route used in organic compound degradation, being higher for fermentative pathways than for oxidative ones. CER and CTR can be described by similar equations cited above for oxygen (Eqs. (2) and (3)) with $\mathrm{CO}_{2}$ solubility is being related with pressure by Henry and Dalton laws (Eqs. (4) and (5)). The CER/OUR ratio is defined as the respiratory quotient (RQ), a parameter very important to assess the degree of a substrate oxidation. For instance, the complete microbial glucose oxidation gives an RQ equals to 1 , but RQ can assume greater values when OUR decreases owing, for instance, to oxygen limitation, and thus leading to anaerobic processes with high $\mathrm{CO}_{2}$ production.

In equilibrium with air, the $\mathrm{CO}_{2}$ concentration in aqueous media at atmospheric pressure and $25^{\circ} \mathrm{C}$ is very low $\left(\sim 10^{-5}\right.$ $\mathrm{mol} / \mathrm{L})$ comparatively to $\mathrm{O}_{2}$ concentration $\left(\sim 26.3 \times 10^{-5}\right.$ $\mathrm{mol} / \mathrm{L}){ }^{6}$ This is owing to the difference in partial pressure of each component in the air, being 0.003 and 0.21 bar, respectively, for carbon dioxide and oxygen. However, as $\mathrm{CO}_{2}$ solubility in water is about 2.5-fold higher than the $\mathrm{O}_{2}$ solubility, ${ }^{24}$ the dissolved $\mathrm{CO}_{2}$ in microbial cultures under increased total pressure may significantly increase, particularly for fermentative processes.

In water, besides the aqueous $\mathrm{CO}_{2}$ there exists in solution the ions hydrogen carbonate $\left(\mathrm{HCO}_{3}^{-}\right)$and carbonate $\left(\mathrm{CO}_{3}^{2-}\right)$, according to the following equilibrium relationships:

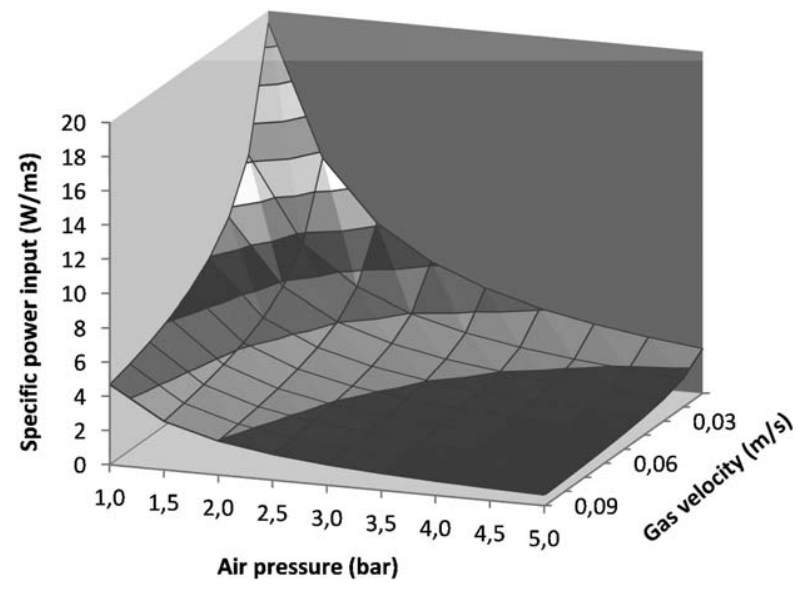

Figure 2. Surface response for a constant value of $O T R / \alpha$ that shows the influence of air pressure and gas velocity in power input needed to achieve a constant OTR.

$$
\begin{gathered}
\mathrm{CO}_{2}(\mathrm{~g}) \leftrightarrow \mathrm{CO}_{2}(\mathrm{aq}) \\
\mathrm{CO}_{2}(\mathrm{aq})+\mathrm{H}_{2} \mathrm{O}(\mathrm{l}) \leftrightarrow \mathrm{H}_{2} \mathrm{CO}_{3}(\mathrm{aq}) \\
\mathrm{H}_{2} \mathrm{CO}_{3}(\mathrm{aq}) \leftrightarrow \mathrm{HCO}_{3}^{-}(\mathrm{aq})+H^{+}(\mathrm{aq}) \\
\mathrm{HCO}_{3}^{-}(\mathrm{aq}) \leftrightarrow \mathrm{H}^{+}(\mathrm{aq})+\mathrm{CO}_{3}^{2-}(\mathrm{aq})
\end{gathered}
$$

The limiting step in these reactions is the dissolved $\mathrm{CO}_{2}$ hydration (Eq. (9)), but as the carbonic acid $\left(\mathrm{H}_{2} \mathrm{CO}_{3}\right)$ concentration in equilibrium with dissolved $\mathrm{CO}_{2}$ is very low ( $\sim 2 \times 10^{-3}$ of $\mathrm{CO}_{2}$ concentration), it may be neglected comparatively to the dissolved $\mathrm{CO}_{2}$ concentration.

The equilibrium constants of reactions (Eq. (10)) and (Eq. (11)) in water, at $25^{\circ} \mathrm{C}$, are $5 \times 10^{-7}$ and $5.6 \times 10^{-11} \mathrm{~mol} /$ $\mathrm{L}$, respectively, which show that the ionic equilibria of $\mathrm{CO}_{2}$ can be neglected at $\mathrm{pH}$ of lower than 5. However, from $\mathrm{pH}$ 7 to 9 , the ion $\mathrm{HCO}_{3}^{-}$is predominant and above $\mathrm{pH} 11$ the ion $\mathrm{CO}_{3}^{2-}$ is the dominant species. ${ }^{6}$ Thus, in yeast cultures, namely in ethanolic fermentation, which occurs from $\mathrm{pH} 4.0$ to 5.5 , the dissolved $\mathrm{CO}_{2}$ is found in nondissociated form. In turn, in bacterial cultures with $\mathrm{pH}$ values near neutrality, the $\mathrm{CO}_{2}$ dissociation to hydrogen carbonate cannot be neglected. Thus, increasing $p \mathrm{CO}_{2}$ has an indirect impact on bioprocesses owing to the $\mathrm{pH}$ changes that may occur, but it would be more relevant for bacterial cultures growing at $\mathrm{pH}$ values around or above 7 .

\section{Effect on microbial cells}

The dissolved oxygen and carbon dioxide concentration may limit microbial activity and consequently metabolic behavior. In some processes, a reduction of growth and production rates was observed, thus affecting the productivity. In addition, there are processes where oxygen limitation leads to a metabolic pathway shift, ${ }^{25,26}$ resulting in the formation of by-products and reducing the product yield. As a consequence, analysis of the pressure effects on cell physiology must be considered.

For the range of air pressures up to 15 bar, some studies have been published regarding the effects of moderate pressure on microbial (bacteria and yeasts) growth and product formation (Table 1). Results from these articles demonstrate that the effect of air pressure on microbial cultures is rather dependent on the microbial species as it is detailed in the next section. 
Table 1. Effects of increased air pressure on microbial growth and product formation

\begin{tabular}{|c|c|c|c|c|}
\hline Microorganism & $P$ (bar) & $\begin{array}{l}\text { Mode of } \\
\text { Operation }\end{array}$ & Effect & References \\
\hline Arxula adeninivorans & 5 & Fed-batch & Maximum cell density $(225 \mathrm{~g} / \mathrm{L})$ ever reported for this strain & Knoll et al. ${ }^{8}$ \\
\hline C. glutamicum & 10 & Fed-batch & Maximum cell density $(226 \mathrm{~g} / \mathrm{L})$ ever reported for this strain & Knoll et al. ${ }^{8}$ \\
\hline E. coli & 4.8 & Fed-batch & $\begin{array}{l}\text { 2.5- and 4-Fold improvement in cell density and cytochrome } \\
\text { b5 productivity, respectively }\end{array}$ & Belo and Mota $^{27}$ \\
\hline E. coli & 4.8 & Batch & $\begin{array}{l}\text { The cellular growth was not inhibited and acetate } \\
\text { accumulation was prevented }\end{array}$ & Knabben et al. ${ }^{28}$ \\
\hline P. fluorescens & 8 & Continuous & Complete inhibition of cellular growth & Onken $^{29}$ \\
\hline P. putida & 11 & Batch & $40 \%$ Decrease on specific growth rate & Knoll et al. ${ }^{3}$ \\
\hline P. putida & 7 & Continuous & $\begin{array}{l}\text { The cellular growth was not inhibited and a little increase of } \\
\text { medium-chain-length polyhydroxyalkanoate volumetric } \\
\text { productivity was observed }\end{array}$ & Follonier et al. ${ }^{19}$ \\
\hline S. aureofaciens & 8 & Continuous & $\begin{array}{l}\text { Increase of lag phase and twofold improvement on } \\
\text { tetracyclines production }\end{array}$ & Liefke et al. ${ }^{30}$ \\
\hline S. rimosus & 8 & Continuous & $\begin{array}{l}\text { Complete inhibition of cell growth and no tetracyclines were } \\
\text { produced }\end{array}$ & Liefke et al. ${ }^{30}$ \\
\hline Thermus sp. & 5 & Batch & 2.2-Fold improvement in cell mass productivity & Belo et al. ${ }^{1}$ \\
\hline C. utilis & 12 & Fed-batch & $\begin{array}{l}\text { 1.5-Fold improvement in cell density and strong inhibition on } \\
\text { ethanol production }\end{array}$ & Pinheiro et al. ${ }^{31}$ \\
\hline K. marxianus & 6 & Batch & $\begin{array}{l}\text { The cellular growth was not inhibited and a threefold } \\
\text { improvement in } \beta \text {-galactosidase productivity was attained }\end{array}$ & Pinheiro et al. ${ }^{5}$ \\
\hline P. pastoris & 1.9 & Fed-batch & $\begin{array}{l}\text { 1.1- and 1.4-Fold improvement in cell density and Thai } \\
\text { Rosewood } \beta \text {-glucosidase yield, respectively }\end{array}$ & Charoenrat et al. ${ }^{2}$ \\
\hline P. pastoris & 5 & Fed-batch & 1.6-Fold improvement in cell mass yield and final biomass & Lopes et al. ${ }^{20}$ \\
\hline S. cerevisiae & 6 & Batch & 1.5-Fold Improvement in specific growth rate & Coelho et al. ${ }^{32}$ \\
\hline S. cerevisiae & 10 & Fed-batch & $\begin{array}{l}\text { 1.5-Fold improvement in cell mass yield and specific growth } \\
\text { rate; } 1.9 \text {-fold decrease in ethanol yield }\end{array}$ & Belo et al. ${ }^{33}$ \\
\hline S. cerevisiae & 15 & Fed-batch & $\begin{array}{l}\text { 2.9-Fold decrease in cell mass yield and drastic reduction in } \\
\text { specific growth rate; } 1.8 \text {-fold decrease in ethanol yield }\end{array}$ & Belo et al. ${ }^{33}$ \\
\hline S. cerevisiae & 15 & Batch & 4.5-Fold decrease in cell density & Dong et al. ${ }^{34}$ \\
\hline Y. lipolytica & 6 & Batch & $\begin{array}{l}\text { 3.4- and 5-Fold improvement in specific growth rate and cell } \\
\text { density, respectively }\end{array}$ & Lopes et al. ${ }^{35}$ \\
\hline Y. lipolytica & 8 & Batch & $\begin{array}{l}\text { The cellular growth was not inhibited and a } 5.5 \text {-fold } \\
\text { improvement in lipase activity was obtained }\end{array}$ & Lopes et al. ${ }^{4}$ \\
\hline
\end{tabular}

\section{Effect of oxygen partial pressure}

Bacteria. Some references are available about the effect of increased air pressure on bacterial growth with the mesophile E. coli, the most studied species. It is well known that, for $E$. coli, one of the most popular hosts in molecular biology, the cellular growth is affected by oxygen availability. ${ }^{36}$ This fact is important because most recombinant proteins expressed in this microorganism are intracellular despite all the efforts deployed so far to improve heterologous protein secretion in E.coli. ${ }^{37}$ One of the challenges to maximize cell densities is to ensure an adequate oxygen supply to the culture medium.

Several values of air pressure have been used in E. coli cultivation, from 1.6 to 11 bar. In general, the pressurization of bioreactor did not inhibit the cellular growth or even led to an increase of cell density. ${ }^{8,17,27,28,38,39}$ However, some authors reported a slight decrease in final biomass in batch cultivations up to 4 bar. $^{27}$ Besides cellular growth, recombinant compounds, such as cytochrome $b 5,{ }^{27}$ pDNA vaccine, ${ }^{38}$ and human-like collagen protein, ${ }^{39}$ could be successfully produced under increased air pressure. In addition, the fully aerobic conditions achieved under increased air pressure prevent the accumulation of by-products such as acetate ${ }^{28}$ or acetic acid. ${ }^{17}$

The cellular growth of other bacterial species, such as Streptomyces rimosus ${ }^{30}$ and Pseudomonas fluorescens, ${ }^{29}$ was strongly inhibited when cultured at 8 bar of air pressure (1.6 bar of $\mathrm{O}_{2}$ partial pressure). However, the same effect was observed when pure $\mathrm{O}_{2}$ at 1.2 bar $^{30}$ and 1.15 bar $^{29}$ was used for culture aeration. These results demonstrate that the oxygen partial pressure and not the total air pressure is the cause for growth inhibition. Also, Follonier et al. ${ }^{19}$ proved that total pressure $(7$ bar) by itself is not an issue for the $P$. putida cells but rather the high $\mathrm{O}_{2}$ tension. There are species, such as Methylomonas clara, where lower values of $\mathrm{O}_{2}$ partial pressure $\left(0.7\right.$ bar) led to a significant growth inhibition. ${ }^{40}$ In contrast to what was observed for cellular growth, the increase of oxygen availability had a positive effect on the production of tetracyclines by $S$. rimosus at 1.2 bar of pure $\mathrm{O}_{2}$ and by $S$. aureofaciens at 8 bar of air pressure. ${ }^{30}$

Thermophilic microorganisms are important sources of thermostable enzymes and, in spite of their adaptation to low gas concentrations in natural habitat owing to high temperatures, considerably high values of OUR have been reported for some aerobic strains. ${ }^{41}$ Therefore, the industrial cultivation of thermophiles in high-cell-density systems can present limitations of oxygen transfer. A 2.2-fold improvement in cell mass productivity on Thermus sp. RQ-1 batch and fedbatch cultivation was obtained raising the air pressure up to 5 bar. ${ }^{1}$ Thus, over-pressurization of air in bioreactors is very useful for aerobic thermophilic microorganisms for OTR improvement, with the additional advantage of preventing volatile compound losses by evaporation.

Yeasts. In Saccharomyces cerevisiae cultures pressurized with air up to $10 \mathrm{bar}$, an improvement in specific growth rate and cell mass yield was reported. ${ }^{18,32,33,42}$ Above 15 bar of air pressure, a 2.9- and 4.5-fold decrease in cell mass yield $^{33}$ and cell density, ${ }^{34}$ respectively, was observed in batch cultures of $S$. cerevisiae. However, Pinheiro et al. ${ }^{43}$ observed a 2.2-fold reduction in specific growth rate in batch cultures at 6 bar of air pressure compared to the experiment under 1.2 bar. In contrast, the negative effect of increased 
air pressure on ethanol yield was reported by several authors. ${ }^{33,43}$ The oxygen pressure above 3 bar had a strong inactivation effect on the yeast, using either pure oxygen $^{18,32,42-44}$ or air at $15 \mathrm{bar}^{18}{ }^{18}$ which indicates that the main cause of cell inhibition is the oxygen toxicity not the total air pressure.

There is evidence that the nature of the gas, and not the total pressure, is critical for the yeast cell cycle development and morphology. Although S. cerevisiae cells exposed to pure oxygen above 3 bar seem to delay the bud detachment, ${ }^{44}$ reduce the percentage of budding cells, ${ }^{32}$ and increase the fraction of cells with more than four bud scars (old cells) ${ }^{33}$ in systems with air up to 10 bar, a decrease of bud separation time occurred, ${ }^{44}$ no differences in percentage of budding cells were observed, ${ }^{32}$ and the majority of the cells were young with no bud scars or with only one bud scar. ${ }^{33}$ However, for experiments with 15 bar of air pressure $\left(\mathrm{O}_{2}\right.$ partial pressure, $\left.3 \mathrm{bar}\right)$, the genealogical age profile of cell population is similar to that obtained with 3 bar of pure oxygen. ${ }^{33}$ Furthermore, Dong et al. ${ }^{34}$ reported that under atmospheric pressure, $S$. cerevisiae cells were round and smooth, but at 5 bar the cells became more flat and with the pressure increasing up to $15 \mathrm{bar}$, an increase on disrupted cell membrane structures and cell death was observed. Belo et al. ${ }^{33}$ reported a decrease in $S$. cerevisiae cell size with the raise of air pressure from 1 to 15 bar that attributed to cell compression, which could result not directly from pressure, but from the oxidative stress that causes damage to membrane cells by different ways such as lipid peroxidation, changes in the membrane permeability and fluidity, leading to internal components loss.

Several other yeast species different from S. cerevisiae, such as Kluyveromyces marxianus, ${ }^{45}$ Candida utilis, ${ }^{31}$ and Pichia pastoris, ${ }^{2,20}$ were cultured under increased air pressure and it was proved possible to overcome the oxygen limitation and to improve cellular growth. The ethanol production was considerably reduced in $K$. marxianus ("Kluyver-negative") batch cultures under 6 bar of air pressure, ${ }^{45}$ and in $C$. utilis fed-batch process at 12 bar of air pressure. ${ }^{31}$ Furthermore, the specific $\beta$-galactosidase productivity by $K$. marxianus ("Kluyver-positive") increased threefold using a 6 bar of air pressure, ${ }^{5}$ and a 1.4-fold improvement in recombinant Thai Rosewood $\beta$-glucosidase yield by $P$. pastoris was obtained raising the air pressure from 1.2 to 1.9 bar. $^{2}$

Other nonconventional yeast, Yarrowia lipolytica, has been successfully cultivated under hyperbaric conditions. A fivefold enhancement of the cell dry-weight at 6 bar of air pressure was obtained compared with the experiments at 1 bar, ${ }^{35}$ but increasing air pressure up to 8 bar did not improve the growth of $Y$. lipolytica. ${ }^{4}$ The yeast cells remained oval at $<8$ bar and a cell size decrease was found for this pressure. ${ }^{4}$ The production of extracellular lipase and protease enzymes by $Y$. lipolytica W29 was distinctly affected by the raise of air pressure up to 8 bar, which indicates that hyperbaric air can be an important factor for enzyme production, and can be used as a control parameter for lipase production optimization. Although lipase activity was clearly enhanced by pressure, the protease production decreased with the raise of air pressure from 4 to 8 bar. $^{4}$ Lopes et al. ${ }^{35}$ proved the ability of $Y$. lipolytica cells to quickly adapt to hyperbaric air conditions. The application of air pressure has been explored in $Y$. lipolytica cultures for several purposes. For instance, in aroma production from methyl ricinoleate biotransformation, the increase of oxygen owing to the air pressure raise up to 5 bar influenced $\beta$-oxidation pathway shifting $\gamma$-decalactone production to the formation of other compounds such as dec2-en-4-olide and dec-3-en-olide. ${ }^{46}$

\section{Effect of carbon dioxide partial pressure}

Carbon dioxide is a product of the cellular metabolic activity of growing cells, and in common aerobic processes involving gas sparging, most carbon dioxide produced by the cells is rapidly stripped out of the medium by the sparged gases. However, the increase in $\mathrm{CO}_{2}$ partial pressure owing to the raise of total pressure enhances the dissolved $\mathrm{CO}_{2}$ in the medium. For high-pressure fermentations up to 11 bar, the partial pressure of carbon dioxide can reach values of 0.8 bar or even high, ${ }^{3}$ which may have metabolic consequences to the cells. It is known that $\mathrm{CO}_{2}$ is inhibitory to the growth of a number of microorganisms and this effect has been exploited for the preservation of packed foods from bacterial spoilage. ${ }^{47}$ However, in those cases, pure $\mathrm{CO}_{2}$ is usually applied and $\mathrm{CO}_{2}$ partial pressure is significantly higher than in systems where air at moderate pressures is used.

To simulate the $\mathrm{CO}_{2}$ levels that can arise by high RQ cultures at elevated air pressures, $S$. cerevisiae cultures were aerated with gas mixtures containing 4 and $8 \% \mathrm{v} / \mathrm{v} \mathrm{CO}_{2}$ at 6 bar of total pressure. ${ }^{18}$ The raise of $\mathrm{CO}_{2}$ partial pressure to 0.48 bar decreased overall cell mass yield ${ }^{18}$ and the specific growth rate, ${ }^{42}$ but increased ethanol mass yield and had no effect on the cell viability of the yeast. ${ }^{18}$ Knoll et al. ${ }^{8}$ reported that in fed-batch cultures of $S$. cerevisiae, at 5 bar of air pressure, the carbon dioxide partial pressure in the gas phase attained the maximum value of 0.42 bar, which was not inhibitory for cellular growth. However, Campelo and Belo ${ }^{42}$ observed that the increase of $\mathrm{CO}_{2}$ partial pressure up to 0.48 bar led to a significantly decrease on baker's yeast viability, but the leavening ability of the cells remained unchanged compared to the control (cells not exposed to hyperbaric gases). The $\mathrm{CO}_{2}$ production rates in dough with baker's yeast exposed to air at 1.2 and 6 bar $(0.00036$ and 0.0018 bar of $p_{\mathrm{CO}_{2}}$, respectively) were quite close to the value obtained with cells not exposed (control). ${ }^{42}$

Cellular inhibition has been reported for higher $\mathrm{CO}_{2}$ pressure, such as at 6 bar where a strong inhibiting effect on specific growth rate of $S$. cerevisiae, ethanol production, and biomass yield was observed. ${ }^{32,44}$ In addition, cell division was inhibited and cell size decreased, ${ }^{32}$ which has been explained by the loss of intracellular biomolecules of low molecular weight since $\mathrm{CO}_{2}$ compression and decompression inside the cell may be responsible for the cell membrane leakage.

In Thermus sp. RQ-1 cultures, a $\mathrm{CO}_{2}$ partial pressure of 0.2 bar (enriched inlet gas with $4 \% \mathrm{CO}_{2}$ at 5 bar of total pressure) had no inhibitory effect on cell growth and a slightly improvement of cell mass production was observed. ${ }^{1}$ The pressurization of Corynebacterium glutamicum fed-batch cultures with air up to 10 bar raised the carbon dioxide partial pressure in the gas phase up to maximum values of 0.6 bar, but no inhibitory effect on growth behavior was observed. Also, the E. coli fed-batch growth was not inhibited by a carbon dioxide partial pressure of 0.8 bar achieved in cultures with air at 11 bar. $^{8}$

Most of the studies regarding the effect of carbon dioxide partial pressure in microbial growth have been performed at 
atmospheric pressure, by enriching the inlet gas with $\mathrm{CO}_{2}{ }^{40}$ In a culture of Bacillus caldolyticus aerated with atmospheric air mixed with $5 \% \mathrm{CO}_{2}\left(p_{\mathrm{CO}_{2}}, 0.05\right.$ bar $)$, the final cell dry weight was not affected, and the $\alpha$-amylase and protease activity was enhanced by 22 and $43 \%$, respectively. Above this $\mathrm{CO}_{2}$ partial pressure, the maximum $\alpha$-amylase levels were decreased. ${ }^{48}$

It has been reported that high $\mathrm{CO}_{2}$ levels inhibit the $E$. coli growth and increase the acetate accumulation. Baez et al. ${ }^{49}$ observed that as dissolved carbon dioxide increased up to 0.3 bar, the specific growth rate decreased, the acetate accumulation was enhanced, and the time for onset of recombinant green fluorescent protein increased. The maximum biomass yield on glucose and recombinant protein concentration were affected by dissolved $\mathrm{CO}_{2}$ concentration above 0.07 and 0.15 bar, respectively. These inhibitory effects were attributed to the increase of transcription of acid stress genes, to downregulated tricarboxylic acid cycle genes, and upregulated poxB (gene from pathway of production and consumption of acetate). However, other authors observed a slight increase in biomass yield under $\mathrm{CO}_{2}$ partial pressure of 0.2 bar, even when a large fraction of glucose was excreted as acetic acid. Such behavior was attributed to $\mathrm{CO}_{2}$ fixation by anaplerotic pathway when $E$. coli was exposed to elevated $\mathrm{CO}_{2}{ }^{50}$

The response of microorganisms to an increased $p_{\mathrm{CO}_{2}}$ also depends on the carbon source used during the fermentation as described by Bäumchen et al. ${ }^{51}$ The authors observed that a $p_{\mathrm{CO}_{2}}$ of about $0.2-0.3$ bar enhanced the maximum growth rate $\left(\mu_{\max }\right)$ of $C$. glutamicum on lactate, and even at $p_{\mathrm{CO}_{2}}$ of 0.81 bar, $86 \%$ of maximum growth rate was achieved compared to aeration with normal air. In contrast, with glucose as carbon source $\mu_{\max }$ decreased with $p_{\mathrm{CO}_{2}}$ above 0.14 bar, and at 0.81 bar the value was only $60 \%$ of $\mu_{\max }$ obtained in aeration with air.

Generally, the metabolically produced $\mathrm{CO}_{2}$ will not be a constraint for hyperbaric air utilization in high-cell-density aerobic cultures as the exit gas of an aerobic culture in an industrial bioreactor commonly does not have more than $3 \%$ $\mathrm{v} / \mathrm{v}$ of $\mathrm{CO}_{2}{ }^{6}$ Thus, $\mathrm{CO}_{2}$ partial pressure inside a bioreactor at 10 bar would attain the maximum value of 0.30 bar, which is in the range of $p_{\mathrm{CO}_{2}}$ values tested in the studies above and that do not cause cellular inhibition for several microorganisms.

Antioxidant response. As discussed above, the use of increased air pressure in bioreactors leads to an increase in dissolved oxygen. In several cases, increased $\mathrm{O}_{2}$ partial pressure is toxic to aerobic cultures and inhibits microbial growth and product formation. ${ }^{6}$ Molecular oxygen is relatively unreactive and harmless in its ground state, but can undergo partial reduction to form a number of ROS, such as superoxide anion $\left(\mathrm{O}_{2}^{-}\right)$and hydrogen peroxide $\left(\mathrm{H}_{2} \mathrm{O}_{2}\right)$, which can further react to produce the highly reactive hydroxyl radical $(\mathrm{OH}){ }^{52}$

Oxidative stress is caused by cell exposure to ROS and has been well described in the literature. ${ }^{52-55}$ ROS can damage proteins by causing modifications of amino acid side chains, fragmentation of the polypeptide backbone, and formation of crosslinks between proteins. ${ }^{56}$ In addition, ROS can modify sugars and bases in DNA, which lead to DNA chain breaks $^{57}$ and cause lipid peroxidation in cell membranes. ${ }^{58}$ To protect against the damage caused by oxidative stress, cells possess a number of biochemical systems, including enzymes (catalase, superoxide dismutase [SOD], and glutathione reductase), as well as the nonenzymatic protective molecules (thioredoxin and glutathione), most of which are expressed at low levels during normal growth. ${ }^{59,60}$ In response to elevated concentrations of ROS, cells alter the expression of genes encoding antioxidant defense mechanism and genes encoding enzymes, which repair and detoxify the resulting cellular damage.

Glutathione ( $\gamma$-glutamyl-L-cysteinylglycine, GSH) acts as a radical scavenger, with the redox-active sulfhydryl group reacting with oxidants to produce reduced glutathione (GSSG). ${ }^{61}$ SOD is a metalloenzyme that detoxifies superoxide radicals by converting them to hydrogen peroxide and oxygen. ${ }^{62}$ Catalases are ubiquitous enzymes that protect aerobic organisms from the toxic effects of $\mathrm{H}_{2} \mathrm{O}_{2}$ by catalyzing the conversion of $\mathrm{H}_{2} \mathrm{O}_{2}$ to molecular $\mathrm{O}_{2}$ and $\mathrm{H}_{2} \mathrm{O}$. ${ }^{63}$ The enzyme glutathione reductase is primarily responsible for the reduction of oxidized glutathione and maintenance of the GSH/GSSG ratio in cells. ${ }^{64}$

For E. coli, it was reported that cells overproducing SOD were more sensitive to the generators of superoxide anions. ${ }^{65}$ The increase of total pressure and oxygen tension in $E$. coli cultures leads to an induction of the antioxidant enzyme $\mathrm{SOD},{ }^{27,66}$ but it was reported that catalase is not very important in defending this bacteria against oxidative stress. ${ }^{66}$ Induction of SOD by pressurized oxygen was also reported by Taniguchi et al. ${ }^{67}$ for Streptococcus lactis cells. The cultivation of Thermus sp. RQ-1 under increased air pressure led to a fourfold increase of SOD activity, but the catalase activity values were very low, probably indicating that there are other peroxidases more important for the elimination of $\mathrm{H}_{2} \mathrm{O}_{2}$.

During fed-batch cultivation of $S$. cerevisiae, mitochondrial $\mathrm{SOD}^{33,43}$ and glutathione reductase ${ }^{43}$ were induced by hyperbaric air and pure $\mathrm{O}_{2}$, but cytosolic SOD and catalase activities increased only in pure oxygen. ${ }^{43}$ However, Lee and $\operatorname{Hassan}^{68}$ reported that the exposure of cells to $100 \% \mathrm{O}_{2}$ repressed the formation of catalase although SOD has been induced. The culture of $S$. cerevisiae under hyperbaric conditions up to 10 bar also induced an increase of intracellular GSH and trehalose accumulation and improved the trehalose synthase activity. $^{34}$

Cultures of $K$. marxianus under moderate pressures respond to the increase of oxygen partial pressure by enhancing the induction of SOD, catalase, and glutathione reductase. 5,45 Furthermore, it was reported that when mitochondrial SOD was at a low activity level, glutathione reductase and catalase were at high activity levels; however, when cytosolic SOD was induced at a high level, the other enzymatic activities decreased. $P$. pastoris and $Y$. lipolytica cells, cultured under increased air pressure, respond against superoxide stress, enhancing the production of SOD, catalase, and glutathione reductase, as well the accumulation of intracellular GSH. ${ }^{35,69}$ In addition, the extent of lipid peroxidation was lower in the cells exposed to hyperbaric air than those exposed to hydrogen peroxide and paraquat. ${ }^{69}$

The above-described data indicate that the defensive mechanisms of the microbial species against oxidative stress were effective, and cells could cope with increased air and $\mathrm{O}_{2}$ pressure at moderate levels.

Increased air pressure and dissolved oxygen may induce stress and affect translation and protein synthesis, in addition to the changes at the mRNA level when varying from 
optimal values. $^{70,71}$ Different from temperature, $\mathrm{pH}$, osmolarity, or hydrostatic pressure, there are few studies about the effect of moderate pressure (1-15 bar) on the transcriptome of bacteria or yeasts.

Cultivations of $P$. putida carried out at 7 bar revealed the induction of the sigma factor responsible for heat-shock response $(\mathrm{RpoH})$ and of the heat-shock proteins (HtpG, GrpE, GroES, and GroEL), as well as the upregulation of ROS detoxification, hypothetical proteins, and transcription genes. In addition, genes coding for sensing proteins and for proteins located in the cell envelope exhibited the highest significant differential expression compared to the control (air pressure, 1 bar). ${ }^{70}$

$E$. coli cells possess a specific defense against superoxide, mediated by the two-stage SoxRS system (regulates the expression of a major outer membrane protein) and another against peroxides, controlled by the transcriptional activator OxyR (controls the genes encoding HPI catalase, glutathione reductase, among others). ${ }^{72}$ The $\mathrm{O} x y R$ genes have also been identified in Gram-positive bacteria, including Mycobacteria and Streptomyces. ${ }^{73}$ As the increased oxygen partial pressure enhances the superoxide and, consequently, the peroxide anions, it was expected that these systems were activated in bacterial cells exposed to hyperbaric air.

The yeast response to oxidative stress, particularly in $S$. cerevisiae, comprises the activation of transcriptional regulators that lead to induction of antioxidant proteins, such as Yapl, Skn7, Msn2, and Msn4. ${ }^{52,71}$ The expression of a heat shock protein (Hsp104p) was induced in exponentially growing cells submitted to hydrogen peroxide. ${ }^{74}$ Okada et al. ${ }^{75}$ identified 71 essential genes required for hydrogen peroxide tolerance, frequently included in "rRNA processing," "DNA binding," "rRNA synthesis," and "tRNA synthesis" classes, located in the nucleus and nucleolus.

Thus, it is expected that the same defense mechanisms that cells display against oxidative stress in normal pressure will be activated in cells exposed to elevated $p \mathrm{O}_{2}$. The final result in the bioprocesses with microbial cultures in hyperbaric air systems will be a balance of the benefits of the increased oxygen supply and the ability of the cells to cope with the possible increased oxidative stress that might arise.

\section{Conclusions}

Strategies of optimization of bioprocesses based on microbial cells have been focused in the culture medium, strains, and bioreactor operating conditions manipulation, being air pressure neglected as an important factor. As the studies mentioned here have shown, increased air pressure can successfully be applied in microbial cultures, as a way of OTR improvement and oxygen limitation prevention, leading to important gains in bioprocesses productivity. In recent years, this theme has attracted the attention of several authors, and the number of studies on microbial species cultured under hyperbaric conditions has increased. In addition, for many years, stirred reactors operating at rather high pressures have been extensively used in the chemical industry, and the adaptation of such technology to microbial cultures is straightforward. ${ }^{3,17}$

It is generally accepted that air pressure itself, in the range addressed here (up to $\sim 15$ bar), may not affect cell physiology, not giving rise to significant disturbances in molecular systems. The impact of air pressure increase in dissolved gas concentrations, in particular $\mathrm{O}_{2}$ and $\mathrm{CO}_{2}$, is the main reason for the performance variation of cells.

Microorganisms respond diversely to air pressure increase but in general a better performance can be expected for aerobic species growing at low RQ, for example, with high oxygen demand and low carbon dioxide production. Nevertheless, a good knowledge of the effect of $\mathrm{O}_{2}$ and $\mathrm{CO}_{2}$ in the metabolic pathway is essential to better understand all the effects of pressure increase.

In addition, the ability of microorganisms to induce the antioxidant cellular defenses, as a response to hyperoxygenation, has also been demonstrated to be an important feature of cells that may be grown in hyperbaric air systems.

\section{Acknowledgments}

The authors thank the FCT Strategic Project PEst-OE/ EQB/LA0023/2013 and the Project "BioInd-Biotechnology and Bioengineering for improved Industrial and Agro-Food processes, REF. NORTE-07-0124-FEDER-000028," cofunded by the Programa Operacional Regional do Norte (ON.2-O Novo Norte), QREN, FEDER. A special aknowledgement is given to FCT for the support to the improvement of infrastructures awarded by the Project RECI/BBBEBI/0179/2012 (FCOMP-01-0124-FEDER-027462).

\section{Literature Cited}

1. Belo I, Pinheiro R, Mota M. Response of the thermophile Thermus sp. RQ-1 to hyperbaric air in batch and fed-batch cultivation. Appl Microbiol Biotechnol. 2000;53:517-524.

2. Charoenrat T, Ketudat-Cairns M, Jahic M, Veide A, Enfors SO. Increased total air pressure versus oxygen limitation for enhanced oxygen transfer and product formation in a Pichia pastoris recombinant protein process. Biochem Eng J. 2006;30: 205-211.

3. Knoll A, Maier B, Tscherrig H, Buchs J. The oxygen mass transfer, carbon dioxide inhibition, heat removal, and the energy and cost efficiencies of high pressure fermentation. Adv Biochem Eng Biotechnol. 2005;92:77-99.

4. Lopes M, Gomes N, Gonçalves C, Coelho MAZ, Mota M, Belo I. Yarrowia lipolytica lipase production enhanced by increased air pressure. Lett Appl Microbiol. 2008;46:255-260.

5. Pinheiro R, Belo I, Mota M. Growth and $\beta$-galactosidase activity in cultures of Kluyveromyces marxianus under increased air pressure. Lett Appl Microbiol. 2003;37:438-442.

6. Onken U, Liefke E. Effect of total and partial pressure (oxygen and carbon dioxide) on aerobic microbial processes. Adv Biochem Eng Biotechnol. 1989;40:137-169.

7. Bliem R, Katinger H. Scale-up engineering in animal cell technology. Part II. Trends Biotechnol. 1988;6:224-230.

8. Knoll A, Bartsch S, Husemann B, Engel P, Schroer K, Ribeiro B, Stöckmann C, Seletzky J, Büchs J. High cell density cultivation of recombinant yeasts and bacteria under non-pressurized and pressurized conditions in stirred tank bioreactors. J Biotechnol. 2007;132:167-179.

9. Gogate PR, Pandit AB. Survey of measurement technique for gas-liquid mass transfer coefficient in bioreactors. Biochem Eng J. 1999;4:7-15.

10. Gupta A, Rao GA. Study of oxygen transfer in shake flasks using a non-invasive oxygen sensor. Biotechnol Bioeng. 2003; 84:351-358.

11. Pan JG, Rhee JS, Lebeault JM. Physiological constraints in increasing biomass concentration of Escherichia coli B in fedbatch culture. Biotechnol Lett. 1987;9:89-94.

12. Adlercreutz P, Mattiasson B. Oxygen supply to immobilized cells: 1 . Oxygen production by immobilized Chlorella pyrenoidosa. Enzyme Microb Technol. 1982;4:332-336. 
13. Khang YH, Shankar H, Senatore F. Enhanced $\beta$-lactam antibiotic production by coimmobilization of fungus and alga. Biotechnol Lett. 1988;10:867-872.

14. Ibrahim M, Schlegel HG. Efficiency of bovine liver catalase as a catalyst to cleave $\mathrm{H}_{2} \mathrm{O}_{2}$ added continually to buffer solutions. Biotechnol Bioeng. 1980;22:1895-1906.

15. Schlegel HG. Aeration without air: oxygen supply by hydrogen peroxide. Biotechnol Bioeng. 1977;19:413-424.

16. Amaral PFF, Rocha-Leão MHM, Marrucho IM, Coutinho JAP, Coelho MAZ. Improving lipase production using a perfluorocarbon as oxygen carrier. J Chem Technol Biotechnol. 2006;81: 1368-1374.

17. Yang J-D, Wang NS. Oxygen mass transfer enhancement via fermentor headspace pressurization. Biotechnol Prog. 1992;8: 244-251.

18. Belo I, Pinheiro R, Mota M. Fed-batch cultivation of Saccharomyces cerevisiae in a hyperbaric bioreactor. Biotechnol Prog. 2003; 19:665-671.

19. Follonier S, Henes B, Panke S, Zinn M. Putting cells under pressure: a simple and efficient way to enhance the productivity of medium-chain-length polyhydroxyalkanoate in processes with Pseudomonas putida KT2440. Biotechnol Bioeng. 2012;109: 451-461.

20. Lopes M, Mota M, Belo I. Batch and fed-batch growth of Pichia pastoris under increased air pressure. Bioprocess Biosyst Eng 2013;36:1267-1275.

21. Garcia-Ochoa F, Gomez E. Bioreactor scale-up and oxygen transfer rate in microbial processes: an overview. Biotechnol Adv. 2009;27:153-176.

22. Lopes M, Mota M, Belo I. Oxygen mass transfer rate in a pressurized lab-scale stirred bioreactor. Chem Eng Technol. 2013; 36:1779-1784.

23. Sato S, Mukataka S, Kataoka H, Takahashi J. Oxygen absorption rate in an aerated stirred tank under increasing pressure. $J$ Ferment Technol. 1981;59:221-225.

24. Heinzle E, Dunn IJ. Methods and instruments in fermentation gas analysis. In: Rehm HJ, Reed G, Pühler A, Stadler P, editors. Biotechnology. A Multi-Volume Comprehensive Treatise, 2nd ed., Vol. , Measuring, Modelling and Control (Schügerl K, editor). Weinheim: VCH 1993:27-74.

25. Doelle HW, Ewings KN, Hollywood NW. Regulation of glucose metabolism in bacterial systems. Adv Biochem Eng Biotechnol. 1982;23:1-36

26. Futatsugi M, Ogawa T, Fukuda H. Scale-up of glucoamylase production by Saccharomycopsis fibuligera. J Ferment Bioeng. 1993;76:419-422.

27. Belo I, Mota M. Batch and fed-batch cultures of E. coli TB1 at different oxygen transfer rates. Bioprocess Eng. 1998;18:451455.

28. Knabben I, Regestein L, Marquering F, Steinbusch S, Lara AR, Büchs J. High cell-density processes in batch mode of a genetically engineered Escherichia coli strain with minimized overflow metabolism using a pressurized bioreactor. J Biotechnol. 2010;150:73-79.

29. Onken U. Batch and continuous cultivation of Pseudomonas fluorescens at increased pressure. Biotechnol Bioeng. 1990;35:983989.

30. Liefke E, Kaiser D, Onken U. Growth and product formation of actinomycetes cultivated at increased total pressure and oxygen partial pressure. Appl Microbiol Biotechnol. 1990;32:674-679.

31. Pinheiro R, Lopes M, Belo I, Mota M. Candida utilis metabolism and morphology under increased air pressure up to 12 bar [published online December 4, 2013]. Process Biochem. DOI: 10.1016/j.procbio.2013.11.014.

32. Coelho MAZ, Belo I, Pinheiro R, Amaral AL, Mota M, Coutinho JAP, Ferreira EC. Effect of hyperbaric stress on yeast morphology: study by automated image analysis. Appl Microbiol Biotechnol. 2004;66:318-324.

33. Belo I, Pinheiro R, Mota M. Morphological and physiological changes in Saccharomyces cerevisiae by oxidative stress from hyperbaric air. J Biotechnol. 2005;115:397-404.

34. Dong Y, Yang Q, Jia S, Qiao C. Effects of high pressure on the accumulation of trehalose and glutathione in the Saccharomyces cerevisiae cells. Biochem Eng J. 2007;37:226-230.
35. Lopes M, Gomes N, Mota M, Belo I. Yarrowia lipolytica growth under increased air pressure: influence on enzymes production. Appl Biochem Biotechnol. 2009;159:46-53.

36. Ko Y-F, Bentley WE, Weigand WA. An integrated metabolic modelling approach to describe the energy efficiency of Escherichia coli fermentations under oxygen-limited conditions: cellular energetics, carbon flux, and acetate production. Biotechnol Bioeng. 1993;42:843-853.

37. Karim A, Kaderbhai N, Evans A, Harding V, Kaderbhai MA. Efficient bacterial export of a eukaryotic cytoplasmic cytochrome. Nat Biotechnol. 1993;11:612-618.

38. Lara AR, Knabben I, Regestein L, Sassi J, Caspeta L, Ramírez OT, Büchs J. Comparison of oxygen enriched air vs. pressure cultivation to increase oxygen transfer and to scale-up plasmid DNA production fermentations. Eng Life Sci. 2011;11:382-386.

39. Ma X, Fan D, Shang LA, Cai Q, Chi L, Zhu C, Mi Y, Luo YE. Oxygen transfer rate control in the production of human-like collagen by recombinant Escherichia coli. Biotechnol Appl Biochem. 2010;55:169-174.

40. Puhar E, Lorencez I, Fiechter A. influence of partial pressure of oxygen and carbon dioxide on Methylomonas clara in continuous cultura. Eur J Appl Microbiol Biotechnol. 1983;18:131-134.

41. Cometta S, Sonnleitner B, Fiechter A. The growth behavior of Thermus aquaticus in continuous cultivation. Eur J Appl Microbiol Biotechnol. 1982;15:69-74.

42. Campelo AF, Belo I. Fermentative capacity of baker's yeast exposed to hyperbaric stress. Biotechnol Lett. 2004;26:12371240.

43. Pinheiro R, Belo I, Mota M. Physiological behaviour of Saccharomyces cerevisiae under increased air and oxygen pressures. Biotechnol Lett. 1997;19:703-708.

44. Coelho MAZ, Coutinho JAP, Ferreira EC, Mota M, Belo I. Analysis of the effects of hyperbaric gases on S. cerevisiae cell cycle through a morphological approach. Process Biochem. 2007;42:1378-1383.

45. Pinheiro R, Belo I, Mota M. Air pressure effects on biomass yield of two different Kluyveromyces strains. Enzyme Microb Technol. 2000;26:756-762.

46. Aguedo M, Gomes N, Garcia EE, Waché Y, Mota M, Teixeira JA, Belo I. Decalactone production by Yarrowia lipolytica under increased $\mathrm{O}_{2}$ transfer rates. Biotechnol Lett. 2005;27: $1617-1621$

47. Spilimbergo S, Dehghani F, Bertucco A, Foster NL. Inactivation of bacteria and spores by pulse electric field and high pressure $\mathrm{CO}_{2}$ at low temperature. Biotechnol Bioeng. 2003;82:118-125.

48. Bader J, Skelac L, Wewetzer S, Senz M, Popović MK, Bajpai R. Effect of partial pressure of $\mathrm{CO}_{2}$ on the production of thermostable $\alpha$-amylase and Neutral protease by Bacillus caldolyticus. Appl Biochem Microbiol. 2012;48:182-187.

49. Baez A, Flores N, Bolívar, Ramírez OT. Metabolic and transcriptional response of recombinant Escherichia coli to elevated dissolved carbon dioxide concentrations. Biotechnol Bioeng. 2009; 104:102-110

50. Castan A, Näsman A, Enfors S-O. Oxygen enriched air supply in Escherichia coli processes: production of biomass and recombinant human growth hormone. Enzyme Microb Technol. 2002;30:847-854.

51. Bäumchen C, Knoll A, Husemann B, Seletzky J, Maier B, Dietrich C, Amoabediny G, Büchs J. Effect of elevated dissolved carbon dioxide concentrations on growth of Corynebacterium glutamicum on D-glucose and L-lactate. J Biotechnol. 2007; 128:868-874.

52. Morano KA, Grant CM, Moye-Rowley WS. The response to heat shock and oxidative stress in Saccharomyces cerevisiae. Genetics 2012;190:1157-1195.

53. Li Q, Bai Z, O’Donnell A, Harvey LM, Hoskisson PA, McNeil B. Oxidative stress in fungal fermentation processes: the roles of alternative respiration. Biotechnol Lett. 2011;33:457-467.

54. Lushchak VI. Adaptive response to oxidative stress: Bacteria, fungi, plants and animals. Comp Biochem Phys C. 2011;153: 175-190.

55. Nathan C, Cunningham-Bussel A. Beyond oxidative stress: an immunologist's guide to reactive oxygen species. Nat Rev Immunol. 2013;13:349-361. 
56. Berlett BS, Stadtman ER. Protein oxidation in aging, disease, and oxidative stress. J Biol Chem. 1997;272:20313-20316.

57. Storz G, Christman MF, Sies H, Ames BN. Spontaneous mutagenesis and oxidative damage to DNA in Salmonella typhimurium. Proc Natl Acad Sci USA. 1987;84:8917-8921.

58. Wolff SP, Garner A, Dean RT. Free radicals, lipids and protein degradation. Trends Biochem Sci. 1986;11:27-31.

59. Jamieson DJ. Oxidative stress response of the yeast Saccharomyces cerevisiae. Yeast 1998;14:1511-1527.

60. Oliver AE, Leprince O, Wolkers WF, Hincha DK, Heyer AG, Crowe JH. Non-disaccharide-based mechanisms of protection during drying. Cryobiology 2001;43:151-167.

61. Marchler G, Schuller C, Adam G, Ruis H. A Saccharomyces cerevisiae UAS element controlled by protein kinase A activates transcription in response to a variety of stress conditions. $E M B O$ J. 1993;12:1997-2003.

62. Dellomonaco C, Amaretti A, Zanoni S, Pompei A, Matteuzzi D, Rossi M. Fermentative production of superoxide dismutase with Kluyveromyces marxianus. J Ind Microbiol Biotechnol. 2007;34:27-34.

63. Angelova MB, Pashova SB, Spasova BK, Vassilev SV, Slokoska LS. Oxidative stress response of filamentous fungi induced by hydrogen peroxide and paraquat. Mycol Res. 2005; 109:150-158.

64. Grant CM, MacIver FH, Dawes IW. Glutathione is an essential metabolite required for resistance to oxidative stress in the yeast Saccharomyces cerevisiae. Curr Genet. 1996;29:511-515.

65. Schellhorn HE, Hassan HM. Response of hydroperoxidase and superoxide dismutase deficient mutants of Escherichia coli $\mathrm{K}-12$ to oxidative stress. Can J Microbiol. 1988;34:1171-1176.

66. Gregory EM, Fridovich I. Induction of superoxide dismutase by molecular oxygen. J Bacteriol. 1973;114:543-548.

67. Taniguchi M, Hoshino K, Itoh T. Production of superoxide dismutase in Streptococcus lactis by a combination of use of hyperbaric oxygen and fermentation with cross-flow filtration. Biotechnol Bioeng. 1992;39:886-890.

68. Lee F-JS, Hassan HM. Effect of oxygen tension on stability and expression of a killer toxin chimeric plasmid in a chemostat culture of Saccharomyces cerevisiae. Appl Microbiol Biotechnol. 1987;27:72-74.

69. Lopes M, Mota M, Belo I. Comparison of Yarrowia lipolytica and Pichia pastoris cellular response to different agents of oxidative stress. Appl Biochem Biotechnol. 2013;170:448-458.

70. Follonier S, Escapa IF, Fonseca PM, Henes B, Panke S, Zinn M, Prieto MA. New insights on the reorganization of gene transcription in Pseudomonas putida KT2440 at elevated pressure. Microb Cell Fact. 2013;12:30-47.

71. Vogel C, Silva GM, Marcotte EM. Protein expression regulation under oxidative stress. Mol Cell Proteomics 2011;10: M111.009217.

72. Cabiscol E, Tamarit J, Ros J. Oxidative stress in bacteria and protein damage by reactive oxygen species. Int Microbiol. 2000; $3: 3-8$.

73. Groves MR, Lucana DOO. Adaptation to oxidative stress by Gram-positive bacteria: the redox sensing system HbpS-SenSSenR from Streptomyces reticuli. Appl Microbiol Microb Biotechnol. 2010;1:33-42.

74. Pereira MD, Eleutherio ECA, Panek AD. Acquisition of tolerance against oxidative damage in Saccharomyces cerevisiae. BMC Microbiol. 2001;1:11-20.

75. Okada N, Ogawa J, Shima J. Comprehensive analysis of genes involved in the oxidative stress tolerance using yeast heterozygous deletion collection. FEMS Yeast Res. 2014;14:425-434.

Manuscript received Dec. 18, 2013, and revision received Mar. 12, 2014. 